\title{
Where do we go from here? Ongoing colonialism from Attachment Theory
}

\author{
Peter W. Choate ${ }^{1}$ \\ Brandy CrazyBull, Saaami"'inihkaakii (Head Dress Singing Woman)² \\ Desi Lindstrom, Ninna Pita (Eagle Man) ${ }^{3}$ \\ Gabrielle Lindstrom, Tsapinaki ${ }^{1}$
}

${ }^{1}$ Mount Royal University, Calgary, Canada

2 University of Calgary

${ }^{3}$ Circle Keeper, Mahmawiatoskiwin Program

${ }^{1}$ Indigenous Studies, Mount Royal University

\begin{abstract}
INTRODUCTION: The article challenges the current interpretation of Attachment Theory (AT) which favours placement of Indigenous children in non-Indigenous homes. Historical attempts to assimilate Indigenous populations are examined in relation to ongoing assimilation within child intervention and justice systems. The goal is to stimulate discussion about possible culturally appropriate models to articulate the complex and multiple attachments formed by an Indigenous person who is brought up in an Indigenous community, compared to the popular Western and Eurocentric view of parenting through dyadic attachment derived from AT.
\end{abstract}

METHODS: A review of AT literature examining key questions of cross-cultural applicability validity in relation to Indigenous populations. Consultations were held with Elders from the Blackfoot Confederacy of Alberta as part of the Nistawatsiman project. Data were gathered in a project relating to AT and the Supreme Court of Canada.

FINDINGS: Cultural Attachment Theory is emerging as a preferred way to think of Indigenous contexts as opposed to applying traditional AT. The validity of AT with Indigenous families is likely not valid and perpetuates colonial and assimilative understandings of family, parenting and the place of culture.

CONCLUSIONS: Pan-Indigenous methods bias child intervention, blinding them to the capacity of Indigenous caring systems' capacity to raise their children. The use of AT sustains overrepresentation of Indigenous children in care and continues the colonial practices of fracturing Indigenous caregiving systems which, in turn, creates the patterns for the next generation's over-representation in care. Indigenous ways of knowing and being are required along with Indigenous-based decision making.

KEYWORDS: Indigenous child protection, attachment theory, colonisation, reconciliation

AOTEAROA NEW ZEALAND SOCIAL WORK 32(1), 32-44.

CORRESPONDENCE TO: Peter W. Choate pchoate@mtroyal.ca
The Truth and Reconciliation Commission in Canada ([TRC], 2015), has challenged Canada to address the ongoing colonisation of Indigenous people through child intervention programmes. The need for a decolonised approach is echoed in recent decisions of the Canadian Human
Rights Tribunal ([CHRT] 2016, 2017, 2018, 2019). Not only must the actions of child intervention change but also its foundational understandings and methodologies.

An example of racially biased practices can be seen in the Supreme Court of Canada 
ruling in a criminal matter, Ewert v. Canada (2018, SCC 30). The Court determined that the use of psychometric tools that are not valid for Indigenous peoples creates discriminatory results that potentially bias against this population. This decision led the Canadian Psychological Association and The Psychology Foundation of Canada (2018) to caution about the use of Western theory and practices that are not rooted, nor validated, in Indigenous cultures or world views.

There is an emerging awareness of how Western psychological and social work theories and practices have been contrary to the best interests and rights of Indigenous peoples - thus extending colonisation. This article will compare and contrast the differences in Western theories and Indigenous worldviews as they pertain to child intervention. We will use Attachment Theory (AT) to illustrate the ways in which Western-dominated theories have been imposed upon and disadvantage Indigenous families via the child intervention system. Inge Bretherton (1992), a student of John Bowlby (1969) and Mary Ainsworth, (1964) the major theorists of AT, wrote that researchers need to develop attachment theories that are specifically tailored to different cultures. Our literature reviews and research have failed to identify any validation or norming studies with Canadian Indigenous people. We suggest this will be true of other Indigenous communities elsewhere in the world (Keller, 2018; Keller \& Bard, 2017), including with the Māori (Fleming, 2016). LeGrice, Braun, and Wetherell (2017) describe how unique Māori ways of raising children have been suppressed and invalidated within Western psychological paradigms. If there is to be norming of any Indigenous rooted approach, it should be done from within culture which may include partnering with academic researchers.

\section{Orienting the authors}

Peter Choate is a white settler who is a Professor of Social Work. He grew up on the traditional lands of the Musqueum, Tsel'
Waututh and Squamish peoples. Brandy CrazyBull is an Indigenous woman who is a member of the Kainaiwa First Nation and also has Cree origins. Desi Lindstrom offers lived experience related to the child intervention system. He is an Indigenous man, circle keeper and a guest in traditional Blackfoot territory, a member of the Anishnabe nation and a 60s' Scoop survivor. ${ }^{1}$ Gabrielle Lindstrom is a Blackfoot woman and member of the Kainaiwa First Nation in southern Alberta and an assistant professor of Indigenous Studies.

\section{Attachment theory}

To be clear, we do not dispute AT, although we do question the assumption of universal application (Behrens, 2016; Vicedo, 2017). The notion that children require a place of belonging that supports the development of security, identity and a connection to cultural values are all elements of the theory that seem to resonate across cultural expressions. Children do deserve a secure base which has traditionally been defined as an individual, typically the mother, that the child will use when in need of protection or when starting to explore. The secure base also creates an internal working model of what secure relationships should be like (Ainsworth, 1964). The idea that caregiving will be responsive to the needs of the child resonates although the expression of that will vary (van Ijzendoorn \& Sagi-Schwartz, 2008). Recently, Mesman, van Ijzendoorn, and Sagi-Schwartz concluded that there is a balance of universal trends and contextual determinants (2016, p. 870). In essence, it is the knowing of ways in which there are unique expressions of attachment systems that create space for the specific cultural worldview that can serve to enhance our understandings - rather than restrict them to a Western necessity. A cultural model of attachment may offer a more effective view of the Indigenous experience given that raising an Indigenous child in culture includes multiple attachments, caregivers and identity connections (Hossain \& Lamb, 2019; Lindstrom \& Choate, 2016). 
White, Gibson, Wasatell, and Walsh (2020) review the ways that AT has gained prominence in child protection work, often acting as the source of pivotal evidence before the courts. They describe that the power of the theory has become strong enough to impose a worldview on families and cultures, "with tangible personal, social and relational consequences, without sound empirical, moral and cultural foundations" (p. 125). Referring to disorganised attachment, White, Gibson, and Wastell (2019) show results of attachment assessments' presupposed causal link to child abuse and abusive parenting, although noting that diagnosing disorganised attachment is very difficult with only marginal intercoder reliability (p. 2). Further, disorganised attachment correlates with "socio-economic, and environmental stressors such as poverty, isolation and racism" (p. 7). We add intergenerational traumas upon Indigenous peoples from colonisation as strongly connected to these correlates (TRC, 2015).

Evidence indicates that AT may fail to capture the communal parenting systems of Canadian Indigenous cultures which view family inherently differently from the dyadic view of family which underpins AT using the mother-child pairing (van der Horst, 2011). Caltabiano and Thorpe (2007) help us to understand how attachment assists the child to develop a working model of interaction between self and others in order to address responsiveness and emotional needs. This model acts as a lifelong foundation applied to other important and intimate relationships. Researching the continuity of attachment across childhood is methodologically challenging and the extant research provides, at the least, mixed evidence with regard to continuity.

Choate and Lindstrom (2017) argue that the methodology has not been normed within Indigenous cultures and thus serves to extend colonisation. Thus, our argument is not against attachment but against the methods of defining family, parenting and child rearing from a Eurocentric perspective and then applying that to Indigenous cultures. Child rearing is different in Indigenous cultures but there is no panIndigenous way to describe it (Choate et al., 2019; Lindstrom \& Choate, 2016).

Relative to AT, the leading legal case in Canada is the 1983 Supreme Court of Canada (SCC) decision of Racine vs Woods (1983, 2 SCR 173; Choate et al., 2019). This case concluded that attachment superseded the child's culture by determining that bonding sustains while culture fades. Similar approaches are seen in British courts (White et al., 2020). The SCC has not revisited the issue, but it is time that this occurred. The need for change is also driven by the TRC (2015) and the Canadian Human Rights Tribunal (CHRT, 2016, 2017, $2018,2019)$ calling on the social work and related professions to create non-colonial, non-genocidal approaches to their work. These demand, not only a new relationship between child intervention and Indigenous peoples but an approach that respects their culture and traditions and developing solutions in partnership. Indigenous peoples need to manage their own child intervention and family support systems rooted in their way of knowing. In 2019, Canada passed legislation to permit this, but there are financial, jurisdictional and constitutional issues yet to be addressed. Implementation will likely be slow with the probability that some of these issues will ultimately need resolution at the Supreme Court of Canada.

AT, as developed by Bowlby $(1969,1988)$ and others (Ainsworth, 1967; Ainsworth \& Bell, 1970) use the nuclear family as the normative environment in which the primary attachment relationship is seen. The theory is based upon the Eurocentric notion of family and has failed to consider the culturally based approaches to communal systems relying upon multiple relationships.

\section{Attachment from a cultural perspective}

Simard argues, "the literature has shown AT as an approach has negatively impacted First 
Nation people who are involved with child protection services" (2009, p. 45). It has been used as a mechanism for determining where a child should live. When a child has been removed from an Indigenous family and placed in non-cultural homes, the duration of stay in that home is used to argue that the child has attachment to the foster parent as opposed to the Indigenous system as seen in Racine v Woods (SCC 1983).

Culturally based attachment can reinforce the cultural structural processes in the healthy development of Indigenous children while also seeking to secure the extended relational orientation of family. The child is central to this orientation, the parenting of whom is respectfully understood as raising a gift of the Creator (Lindstrom \& Choate, 2016). This provides an Indigenous child with the ability to have a secure base through which to explore the world through multiple connections (Simard \& Blight, 2011). Neckoway, Brownlee, and Castalan (2007) write, "attachment theory, in contrast, concentrates on the linear relationship between the mother and the infant and does not include in the theory wider social relationships except to suggest that the mother infant relationship becomes a template for all future relationships" (p. 68). This individualistic and narrow conceptualisation of parenting stands in stark contrast to the multiple relational view of Indigenous peoples. Neckoway et al. (2007) also argue that AT is inconsistent for raising Indigenous children in culture. This relational approach is epitomised in the term, all my relations, which sees elders, aunts, uncles, older siblings and cousins supporting the child, even when they are not direct blood relatives. As Weisner (2005) notes, attachment in this context socialises children for trust in multiple relationships, cultural and social contexts. This gives the child place and identity (Neckoway et al., 2007). Shared parenting systems are not unique to Indigenous peoples suggesting attachment security is commonly available through multiple intersections (Keller \& Bard, 2017).
Clearly, culturally based attachment is very different from the Eurocentric model. Cassidy (2016) notes that Inge Bretherton asked in the 1980s, "Is an integrated internal working model of the self-built from participation in a number of nonconcordent relationships? If so, how and when? Or all self-models, developed in different relationships only partially integrated or sometimes not at all?" (p. 32). Cassidy (2016) feels little progress has been made answering these questions. This is consistent with our own work (Choate et al., 2019; Choate \& Lindstrom, 2017; Lindstrom \& Choate, 2016; Lindstrom et al., 2016). Mesman et al. (2016) suggest that examining the child's competency development only on the basis of the infant-mother relationship diminishes the predictive power of attachment. Vicedo (2017) has reviewed the lack of attention paid to cultural variations in parenting which lead to quite different forms of attachment. Indigenous cultures are socially unique and require the specific development of an understanding of attachment patterns relevant to that grouping. Mesman et al. add, "the current cross-cultural database is almost absurdly small compared to the domains that should be covered" (2016, p. 871). Keller (2018) describes attachment as an emotional bond which is available in other than dyadic ways.

We have been unable to find any significant work relative to understanding how to define and measure attachment in Canadian Indigenous populations. Elders tell us that models do exist within their worldviews, but these are not constructs to be measured in Eurocentric ways (Elder Roy Bear Chief, personal communication, May 2018). Indeed, attachment assessment of children is based in research methodology as opposed to clinical validation (Vicedo, 2017). This runs counter to the social work ethics of using evidence-based approaches (Drisko \& Grady, 2019) recognising that the worlds of science and practice are very different (White et al., 2019). What happens in a laboratory setting transfers poorly to the real world of child protection decision 
making (Shemmings \& Shemmings, 2011, as cited in White et al., 2019). In an English case ([2018] EWFC 36) a judge was highly critical of a social worker's use of attachment theory due to the difficulties of operationalising the concepts in meaningful clinical ways.

The labels of various forms of attachment may also be inconsistent with an Indigenous worldview (Weisner, 2005) as are the methods for assessing attachment such as the Strange Situation (Ainsworth, Blehar, Waters, \& Wall, 2015), Adult Attachment Interview (Hesse, 2016; Kaplan \& Main, 1996) or other structured approaches that impose Western knowledge on Indigenous realities. The nuclear family does not apply to the Indigenous world view. It should not be used as a way to assess the family, whether through attachment or other forms of assessment that rely upon Eurocentric definitions of family and child rearing (Choate \& Lindstrom, 2018; Lindstrom \& Choate, 2016). Granqvist et al., a group of 40 leading attachment researchers, argue that disorganised attachment has been misapplied and may have led to harm by failing to contextualise the family, including its economic situation, leading to violations of child and parental human rights (2017, p. 551). The Indigenous peoples that we have worked with struggled with the word attachment or even culturally based attachment as they did not have a word for that in their language. Rather, they speak of "all my relations" as a way to think about the collective belonging and relatedness.

Indigenous culture has been undermined in child intervention and justice systems as an insignificant part of a child's upbringing and has been intentionally erased through assessment practices which are imprinted with the persistent and enduring stamp of colonial assimilation. Simard (2009) notes, "Native adoption and foster placements described the situation as the routine and systematize 'cultural genocide' of Indian people" (Kimmelman, 1985, as cited by Simard, p. 47). While the Canadian government has apologised for assimilative genocide, Indigenous children continue to be significantly over-represented in care.

If TRC (2015) calls to action are to be effective, then the continuation of Eurocentric approaches to child welfare, such as the use of attachment approaches not validated in Indigenous cultures, needs to stop.

\section{A cultural perspective}

Drawing on knowledge shared by elders (Lindstrom \& Choate, 2016), we see that raising a child in an Indigenous culture is a complex web of intersecting connections. Unlike nuclear families, the child is raised by multiple people who have various roles which ultimately support the formation of the entire identity of the child. Children are central as they are the Creator's gift to the family and community. In this context, family means the entire group of people who help raise and who have an impact on the child's well-being. Indigenous families consist of primary caregivers, the child's birth parents, but many Indigenous families consider the parents' brothers and sisters to be called "little fathers and little mothers", rather than the typical name of "aunts and uncles". Indigenous languages capture the web of connections (see Choate, 2019).

Brothers and sisters are not only the child's siblings, but the child's cousins also fall under this title as well. The terms "half-" and "step-" are eliminated when referring to a "half-brother" or "step-sister", for example. Should a parent be unable to care for their child, the child will be raised by another family or community member, who will take that child as their own, not differentiating them from other family members. For example, if a child is placed with an aunt and uncle while the parents seek addiction counselling, that child will be called son or daughter.

Grandmothers and grandfathers are very involved with the raising of the children as 
it is believed that life is an endless cycle of being born and dying. The grandparents are at the end of their cycle and the children are at the beginning of theirs. It is commonly believed that, because one is preparing to leave, and one has just arrived, that the bond between them is the strongest.

If Indigenous populations are using their culture as the foundation for the rules of parenting while the Western/Eurocentric society is using AT as a way of validating their presumptions of parenting, then this creates a divide within the collective whole of society. Due to the lack of Western research regarding Indigenous populations, the validity of culture and parenting is undermined by the dominating Eurocentric view of parenting which also then serves as the basis for child intervention (Choate et al., 2019; Lindstrom et al., 2016; Neckoway, 2011). This leads to justice and child intervention systems negatively perceiving Indigenous peoples as non-suitable parents, driving the practice of Indigenous childapprehensions. Bretherton (1992) further posits that assessments need to be culturally defined in order to capture the different cultural perspectives of attachment. Those who suggest attachment is universal in application, have not proven their case (Vicedo, 2017). The lack of specific validity testing in the Indigenous populations does not mean validity by assumption. Rather, it should mean lack of validity in absence of researching and testing for it. This is an example of structural racism where validity is imposed on Indigenous peoples. Gee and Ford outline this form of racism as "macrolevel systems, social forces, institutions, ideologies, and processes that interact with one another to generate and reinforce inequities among racial and ethnic group" (2011, p. 116).

Children removed from culture, are left untethered to a place or identity. They search for a pathway to who they are and where they belong. This includes connections to culture, but also overcoming trauma, finding connection to the land, tradition and ceremony (See Figure 1).
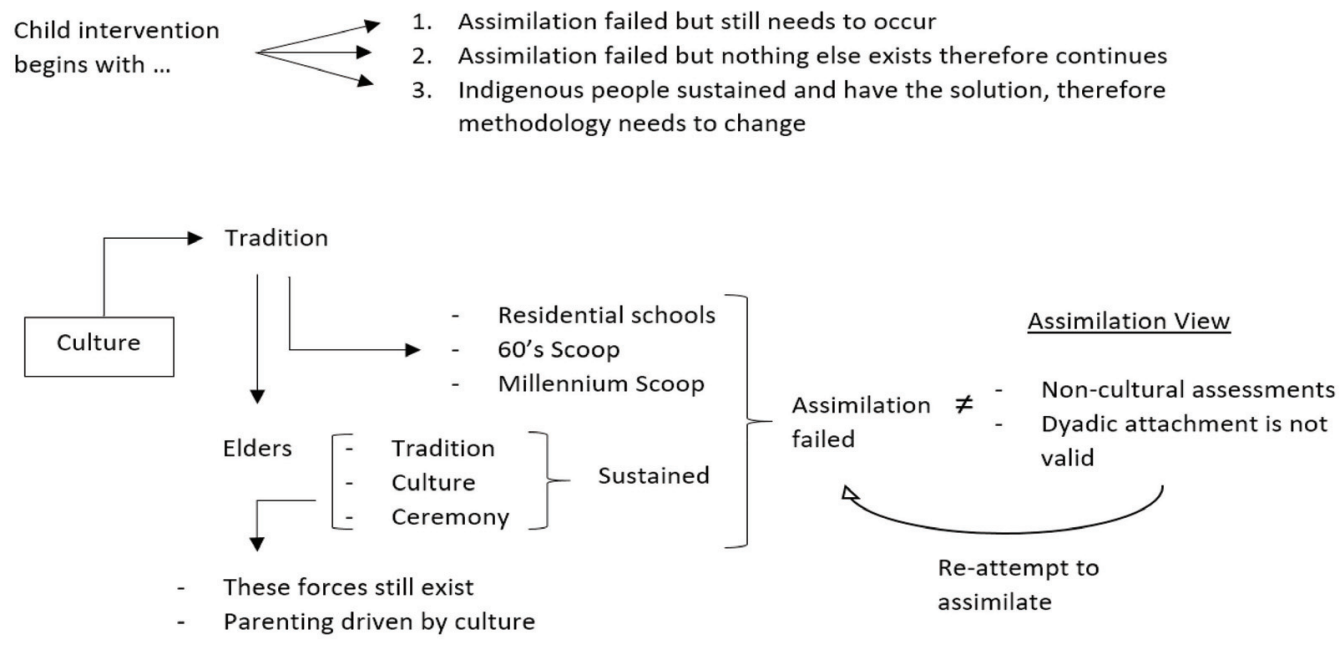

\author{
Creating New Approaches \\ - Decolonized \\ - Do not sustain assimilation effort
}

Figure 1. Sustaining of tradition and Indigenous knowledge while assimilation activities continue. 
Assimilation of Indigenous people has failed but the forces of inter-generational trauma still exist and interrupt the intergenerational transmission of parenting.

The Indigenous culture has persisted for thousands of years. It is important to consider that Indigenous populations always formed their lives around a collective group. Collective parenting is still implemented and practised today (Lindstrom \& Choate, 2016). Children who do not grow up within their community and culture, grow up not knowing the importance of family when it comes to their identity, leading them to not know how to parent (as judged through both Eurocentric and Indigenous views), which later translates into their children being taken away and put into a non-Indigenous home through adoption as the 60s Scoop has shown (Crey \& Fournier, 1998). Following various government apologies, thousands of Indigenous people came forward to share their stories which included abuse, neglect and identity loss. Many of the children from the 60s Scoop never saw their biological family again, leaving them isolated from their Indigenous communities. This led to identity confusion because there was a part of them that was always missing, leaving them to find their culture themselves and try to rebuild what they had lost (Brown $v$. Canada, 2017; CHRT, 2016, 2017, 2018, 2019).

Child intervention is practised today with three main possible directions. As shown in Figure 1, these points are: assimilation failing but having a need for it to occur in

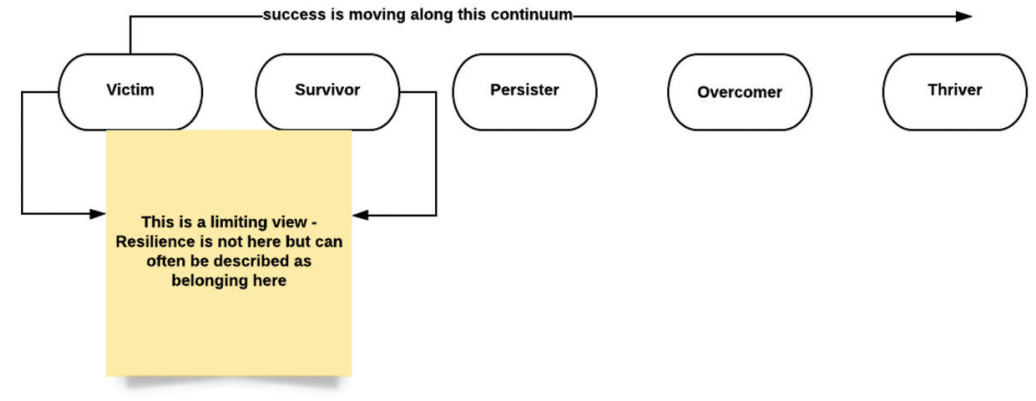

Figure 2. The continuum necessary to move away from Intergenerational Trauma and assimilation efforts. present day; assimilation failing but having nothing else to exist in its place, therefore the continuation of it; or Indigenous people persisting despite assimilation attempts. Figure 1 demonstrates how tradition, ceremony, and culture have been sustained through Elders within the Indigenous population thus helping to defeat attempts of the assimilation processes of residential schools, the 60s Scoop and the millennial scoop. Culture is vital to Indigenous populations and is a lead construct in parenting. The child intervention system is still practising through an assimilating lens via a dyadic approach to attachment by conducting assessments which do not consider culture as a primary factor in parenting. Although the historical attempts at assimilation have failed, the present policies and laws practised within child intervention are attempting to re-assimilate the Indigenous populations into the dominant Western society. Canada needs to be decolonised and there needs to be a new approach by the current child intervention system while considering cultural influences in the Indigenous populations regarding parenting.

Indigenous peoples must recover from the assimilation efforts. Definitions influence conceptualisations of others and determine practices. Thus, we propose this recovery ought to be defined as being more than just surviving. The survivor positioning keeps the Indigenous child and parent trapped in the dynamics of assimilation and intergenerational trauma. As seen in Figure 2, moving beyond that trap requires connections that permit moving towards persistence, overcoming but ultimately thriving. Using colonially based assumptions (such as those raised in this article about AT), denies progression as the power of child protection continues to hold Indigenous people within the victim/survivor dichotomy, a framework in which Indigenous peoples lack control over their own lives. Even the common social work theory of empowerment is colonial as it represents those with the power determining what a legitimate transfer to those without, or with limited, power would be. 
Through the oral, historical stories that were told to us by respected Elders (Lindstrom et al., 2016) within the community and also through the adoption stories of the 60s Scoop (Brown v. Canada, 2017), once a child grows up, even if they had had the most ideal non-Indigenous adoptive parents who cared for them, they always feel as if something is missing. Many adoptees want to know about their biological and cultural roots, and although they may not want a relationship with them, they yearn for a connection (Carriere, 2005; Carriere \& Richardson, 2017; Sinclair, 2007). They want to know where they come from. This statement is derived from the lost cultural identity of Indigenous children who were adopted into nonIndigenous homes as a result of assimilation processes through intergenerational trauma. This statement also shows the importance of culture in Indigenous peoples' lives, especially those of children (TRC, 2015). As one author here (DL), a 60s Scoop survivor, notes, “I just turned 47 and I'm still just a mere child trying to figure out that identity piece." This same author notes that, even with years of progress, he is daily haunted by his losses of knowing in childhood what it meant to be Indigenous. "I didn't know who I was. Because of my name I thought I was Spanish."

In the Nistawatsiman project (Lindstrom et al., 2016), Elders repeatedly spoke of attachment as multi-relational and that parenting reflected that which was passed to the next generation. Other researchers support this view (Neckoway, 2011; Sinclair, 2007; Carriere, 2005).

\section{Pan-Indigenous}

Culture needs to be a priority when placing children - but not through pan-Indigenous practices. The dream catcher is an example of pan-Indigeneity. Over the years it has become a symbol for all Indigenous people. However, the dreamcatcher originated with the Anishinaabe people and has specific cultural purposes. The first is around protecting people when they sleep - a purpose which most people using dreamcatchers are familiar with. The second purpose was that the dreamcatcher traditionally given to a newborn baby and hung from the handle of their cradle board or tikkanagan in order to protect the spirit of the babies since they were not yet given names. In Anishinaabe culture it sometimes was months before a baby was given a name. The dreamcatcher protected the baby from any evil spirit that might want to harm them. The third purpose was that the dreamcatcher was given to a newly married couple to protect the sacredness of their marriage (derived from oral historical stories by respected Elders in the community). Dreamcatchers are mere novelties now and have become appropriated and mass produced to the point that many of them are hanging from a vehicle's mirror. They have become a pan-Indigenous symbol. Although the true culture and meaning of them has been appropriated, the Anishinaabe still hold onto the true meaning.

Elders believe that it is important for an Indigenous person who is from a specific nation to be kept within that nation. This has to do with the importance of identity, and an understanding that, between the different Indigenous nations, there are significant variances in cultural practices. Placing a child who is Cree with a Mohawk family does not constitute a successful placement and can cause confusion for the child. Mohawk and Cree cultures are two different paradigms. Although parallels exist, they should never be equated as the same. Identity has to be at the core of where a child is placed in the permanency planning. The idea that culture and identity has no significance in the placement process has to change. Both the 60s' Scoop and the ongoing over-representation of Indigenous children in care has left generations searching for who they are:

I feel angry and I feel sad. Because, now I know that I'm not the same person that I could have been, and now I'm going to 
have to spend the rest of my life trying to figure out who I am because I lost all of those years while growing up that were essential to finding my identity. So now I feel like I'm even further than where I began as a six-year-old walking into that [foster] home. I feel like six-year-old Brandy had way more than what I have now, before walking into that home. (Author BL speaking of growing up in foster care)

The International Federation of Social Workers (IFSW, 2018) Ethical Principles include: "respect for the inherent dignity and worth of all human beings" (IFSW, Principle 1). The placement of an Indigenous child into a non-indigenous family is at odds with the principles since the practice devalues that child and their origins. It has to be looked at through a non-Eurocentric lens. Identity is different from an Indigenous view as explained by Ned and Frost (2017) who say identity lies in emotional, spiritual, mental, and physical connections to each other and all life, including the spirit world, and in the responsibilities derived from those connections. Culture maintains the connections and responsibilities in combination with ways of life. When children are raised in care by nonIndigenous caregivers, it is impossible to pass this way of learning, being and doing on to them.

Society needs to move away from a panIndigenous imagining of Indigenous cultures, to understand the heterogeneity of who Indigenous people are, where they are from and their line of ancestors. An interrogation of the colonial ideologies that prevent Eurocentric thinkers from understanding Indigenous worldviews is demanded so that Indigenous people have connection to their own stories and place. For example, an Anishinaabe must learn Anishinaabe culture, and language in order to be connected to their ancestors, something which might not be important to other cultures. If the idea of the best interest of the child is a priority, then the future of that child must also be a priority. As an Elder in the Nistwatsiman project noted:

We realized pretty quickly that ceremony was a pretty important part of our lives, and we got involved. And our children were all raised with the ceremonial ways. And I think reconnecting was important. (Lindstrom et al., p. 93)

With the Anishinabe people there is a teaching called "seven generations". In the old days, decisions for the nation were made in consideration of the impacts they would have on seven future generations. We know that how the child is being raised will affect the future of that child. Realising the importance of a child's cultural background should be a factor in the permanency decision as it will be a major factor in the future of the child as they become an adult and impact the generations to come.

\section{Limitations}

There are limitations to the research that need to be considered in order for our arguments to influence change. Validity of Elders' oral testimonies and knowledge would be strengthened if it was recognised by the legal system as a valid source, although it remains an area of some legal challenge (Miller, 2011) even though guidelines exist (Craft, 2013). Recent cases, though, have failed to overcome the preference for scientific evidence as opposed to oral history. Some of the knowledge written comes directly from stories and learnings given by the Elders and cannot be referenced - although there are efforts to gather more stories in a form that can be preserved. The authors are presently working with a Blackfoot Elder regarding the stories of Abraham Maslow's work and the Sikisika Blackfoot people of southern Alberta. Efforts are increasingly needed to show that knowledge appropriated from Indigenous peoples and used as the basis of testimony against Indigenous people may not be accurate in the first place. 
Currently, the 60s' Scoop apology has been given by various Canadian governments yet there is a need for research to be done on the statistics of Indigenous adoption breakdowns, homelessness, and addictions of former adoptees as well as their journeys back to identity. It must also be put forward that Indigenous people are still adapting to a colonised world and are working within the dominant Eurocentric system (Sinclair, 2007). If spiritual practices and world views of other cultures are validated in society then Indigenous culture should have the same validation.

\section{Future directions}

The purpose of this article is to demonstrate that using a universal model originating from a Eurocentric worldview (such as AT) to assess all the diverse cultures is inappropriate. We all have varying cultural ways of knowing. Indeed, this variance is the only thing that separates us. The concept of universality is not very evolved, and we argue for imagining alternate ways of knowing. The question of why the leading theorists of psychology are all from the dominant hegemony should be examined - as should the reasons why one hegemony has the ultimate say in what is right or wrong. When trying to prove something, why is the dominant Eurocentric culture the one to decide the validity of that research? This article is prompting readers to reflect on these questions and realise that it is not a "one size fits all" world. New assessments need to be created by, and for, Indigenous people and need to be recognised as valid tools within the field of social work and law. Choate (2019) shows that other ecological models exist within Indigenous cultures and can act as the basis for modelling assessment. Thus, social work need not be, nor should be, bound by Eurocentric approaches.

An implication of approaching work with Indigenous peoples from a decolonising perspective is that Indigenous people need to drive the solutions. We argue there is too much focus on Indigenising social work when in fact, we suggest that decolonising is the direction. A simple example will illustrate the difference. When a child is placed in a non-Indigenous home, foster parents are asked to work with a cultural plan. This often means attending pow-wows or other ceremonies. A cultural plan that is not rooted in the child's culture cannot act as a force that would sustain the child's Indigenous identity. Thus, we caution that trying to Indigenise Attachment Theory is about trying to fit Indigenous people into the theory and thus sustaining assimilation and colonisation. It is not up to the Eurocentric population to find the solutions. Rather, we see a role for Indigenous researchers and knowledge keepers to begin exploring the stories and traditions of "attachment" and how that might be defined. Lindstrom and Choate (2016) and Choate et al. (2019) have shown some examples of how the connections of the child might be seen and described in assessment. Building such knowledge needs to be relationally based (Stewart \& Allan, 2013) and not be appropriated away from the creators of the knowledge.

A question that arises is whether there is not a growing recognition of the limitations of a Westernized view of AT. There is a shift under way. This is seen in the collection of articles in Keller and Bard's book (2017) and the strong position taken in the article by Granqvist et al. (2017). McCarthy and Gillies (2018) present a vibrant analysis of how the framing of the inquiry (for example, with AT from a Western perspective) frames the questions and thus the possible answers. In this article, we have attempted to show that the framing needs to change when AT is considered to include cultural views, practices and knowledge. If we do not move in that direction, then we sustain a view of attachment that is colonial and diminish the opportunity for larger conversations about the cultural validity of various child protection theories and practices. 


\section{Note}

${ }^{1}$ The term was coined by Patrick Johnston, author of the 1983 report Native Child and the Child Welfare System. It refers to the mass removal in Canada of Aboriginal children from their families into the child welfare system, in most cases without the consent of their families or bands.

Conflict of Interest: The authors declare none.

Funding: No funding was applied to this project

Acknowledgements: We are indebted to the contribution of Elder Roy Bear Chief of the Siksika Nation in Treaty 7 territory in southern Alberta.

Contributions to this work were also made by Taylor Kohler, Felicia Cloete and Parker Tatoulis as part of a social action practicum.

Accepted: 17 March 2020

Published: 14 April 2020

\section{References}

Ainsworth, M. D. (1964). Patterns of attachment behavior shown by the infant in interaction with his mother. MerrillPalmer Quarterly of Behavior and Development, 51-58.

Ainsworth, M. D. S. (1967). Infancy in Uganda: Infant care and the growth of love. Baltimore, MD: Johns Hopkins University Press.

Ainsworth, M. D., \& Bell, S. M. (1970). Attachment, exploration, and separation: Illustrated by the behavior of one-year-olds in a strange situation. Child Development, 41(1), 49-67. http://dx.doi.org/10.2307/1127388

Ainsworth, M. D., Blehar, M. C., Watts, E., \& Wall, S. (2015). Patterns of attachment: A psychological study of the Strange Situation (The classic edition). New York, NY: Routledge.

Behrens, K. Y. (2016). Reconsidering attachment in context of culture: Review of attachment studies in Japan. Online Readings in Psychology and Culture, 6(1). https://doi. org/10.9707/2307-0919.1140

Bowlby, J. (1969). Attachment and loss (Vol. 1: Attachment). New York, NY: Basic Books.

Bowlby, J. (1988). A secure base: Parent-child attachment and healthy human development. New York, NY: Basic Books.

Bretherton, I. (1992). The origins of attachment theory: John Bowlby and Mary Ainsworth. Developmental Psychology, 28(Sep 92), 759-775. Retrieved from http://search.proquest.com/docview/57387969/
Brown v. Canada (Attorney General). (2017). ONSC 251. ON, Canada: Superior Court of Justice. Retrieved from https://www.canlii.org/en/on/onsc/doc/2017/2017onsc25 1/2017onsc251.html?resultIndex=1

Caltabiano, M. L., \& Thorpe, R. (2007). Attachment style of foster carers and caregiving role performance. Child Care in Practice, 13(2), 137-143. https://doi. org/10.1080/13575270701201201

Canada. (2019). An Act respecting First Nations, Inuit and Métis children, youth and families. S.C. 2019 , c. 24. Retrieved from https://laws.justice. gc.ca/PDF/F-11.73.pdf

Canadian Human Rights Tribunal. (2016). First Nations Child and Family Caring Society of Canada et al. v. Attorney General of Canada (for the Minister of Indian and Northern Affairs Canada). 2016 CHRT 2. Ottawa, ON: CHRT. Retrieved from https://fncaringsociety.com/ sites/default/files/2016\%20CHRT\%20Ruling\%20on\%20 FN\%20child\%20welfare\%20case.pdf

Canadian Human Rights Tribunal. (2017). First Nations Child and Family Caring Society of Canada et al. v. Attorney General of Canada (for the Minister of Indian and Northern Affairs Canada). 2017 CHRT 14 Ottawa, ON: Author. Retrieved from https://fncaringsociety.com/sites/ default/files/2017\%20CHRT\%2014.pdf

Canadian Human Rights Tribunal. (2018). First Nations Child and Family Caring Society of Canada et al. v. Attorney General of Canada (for the Minister of Indian and Northern Affairs Canada). 2018 CHRT 4 Ottawa, ON: Author. Retrieved from https://fncaringsociety.com/sites/ default/files/2018\%20CHRT\%204.pdf

Canadian Human Rights Tribunal. (2019). First Nations Child and Family Caring Society of Canada et al. v. Attorney General of Canada (for the Minister of Indian and Northern Affairs Canada). 2019 CHRT 7 Ottawa, ON: Author. Retrieved from https://fncaringsociety.com/sites/ default/files/2019_chrt_7.pdf

Canadian Psychological Association \& Psychology Foundation of Canada. (2018). Psychology's response to the Truth and Reconciliation Commission of Canada's report. Toronto, ON: Author.

Carriere, J. (2005). Connectedness and health for First Nation adoptees. Paediatrics \& Child Health, 10(9), 545. https://doi.org/10.1093/pch/10.9.545

Carriere, J., \& Richardson, C. (2017). Calling our families home: Metis peoples' experience with child welfare. Vernon, BC: J Charlton.

Cassidy, J. (2016). The nature of the child's ties. In J. Cassidy and Phil Shaver (Eds.), Handbook of attachment: Theory, research and clinical applications (3rd ed., pp. 3-24). New York, NY: Guilford.

Choate, P. (2019). The call to decolonise: Social work's challenge for working with Indigenous people. British Journal of Social Work, 49(4), 1081-1099. https://doi. org/10.1093/bjsw/bcz011

Choate, P., Kohler, T., Cloete, F., CrazyBull, B., Lindstrom, D., \& Tatoulis, P. (2019). Rethinking Racine $v$ Woods from a decolonizing perspective: Challenging the applicability of attachment theory to indigenous families involved with child protection. Canadian Journal of Law and Society, 34(1), 55-78. https://doi.org/10.1017/ cls.2019.8 
Choate, P., \& Lindstrom, G. (2017). Parenting capacity assessment as a colonial strategy. Canadian Family Law Quarterly, 37(1), 41-60.

Craft, A. (2013). Reading beyond the lines: Oral understandings and Aboriginal litigation. Paper presented to Public Interest Law, Winnipeg, MB.

Crey, E., \& Fournier, S. (1998). Stolen from our embrace. The abduction of First Nations children and the restoration of Aboriginal communities. Toronto, ON: Douglas \& Mclntyre Publishers.

Drisko, J. W., \& Grady, M. D. (2019). Evidence based practice in clinical social work (2nd ed.). Cham, Switzerland: Springer.

Ewert v. Canada. (2018) SCC 30. Retrieved from https://www.canlii.org/en/ca/scc/doc/2018/2018scc30/ 2018scc30.html?searchUrlHash= AAAAAQARRXdlcnQgdi4gQ2FuYWRhLiAAAAAAAQ\& resultIndex $=1$

Fleming, A. H. (2016). Ngā Tāpiritanga: In what ways are indigenous Māori perspectives on attachment similar to and different from Western psychoanalytic perspectives on attachment and what are the implications for the practice of psychotherapy in Aotearoa New Zealand? A Kaupapa Māori Critical Literature Review (Unpublished master's thesis). Te Wa-nanga Aronui o Tāmaki Makau Rau, Auckland University of Technology, Auckland. Retrieved from https://openrepository. aut.ac.nz/bitstream/handle/10292/10510/FlemingA. pdf?sequence $=3 \&$ isAllowed $=y$

Gee, G., \& Ford, C. (2011). Structural racism and health inequities: Old issues and new directions. Du Bois Review, 8, 115-132. https://doi. org/10.10170S1742058X11000130

GM v Carmarthenshire County Council (2018) EWFC 36. Carmarthenshire, UK: Family Court. Retrieved from https://www.familylaw.co.uk/news_and_comment/gm-vcarmarthenshire-county-council-2018-ewfc-36.

Granqvist, P., Sroufe, A., Dozier, H., Hesse, E., Steele, M., ... Duschinsky, R. (2017). Disorganized attachment in infancy: A review of the phenomenon and its impact for clinicians and policy-makers. Attachment and Human Development, 19(6), 534-558. https://doi.org/10.1080/14 616734.2017 .1354040

Hesse, E. (2016). The adult attachment interview: Protocol, methods of analysis and selected empirical studies: 1985-2015. In J. Cassidy and Phil Shaver (Eds.), Handbook of attachment: Theory, research and clinical applications (3rd ed., pp. 553-597). New York, NY: Guilford

Hossain, B., \& Lamb, L. (2019). Cultural attachment and wellbeing among Canada's Indigenous people: A rural urban divide. Journal of Happiness Studies, Online First. https://doi.org/10.1007/s10902-019-00132-8

International Federation of Social Workers. (2018). Global social work statement of ethical principles. Rheinfelden, Switzerland: Author. Retrieved from https://www.ifsw.org/global-social-work-statement-ofethical-principles/

Kaplan, G. C., \& Main, M. (1966). Adult attachment interview. [Unpublished manuscript]. Department of Psychology, University of California, Berkley. Retrieved from http:// www.psychology.sunysb.edu/attachment/measures/ content/aai_interview.pdf
Keller, H. (2018). Universality claim of attachment theory: Children's socio-emotional development across cultures. PNAS, 115(45), 11414-11419. https://doi.org/10.1073/ pnas. 1720325115

Keller, H., \& Bard, K. (2017). The cultural nature of attachment: Contextualizing relationships and development. Cambridge, MA: MIT Press.

Le Grice, J., Braun, V., \& Wetherell, M. (2017). "What I reckon is, is that like the love you give to your kids they'll give to someone else and so on and so on": Whanaungatanga and mātauranga Māori in practice. New Zealand Journal of Psychology, 46(3), 88-97.

Lindstrom, G., \& Choate, P. (2016). Nistawatsiman: Rethinking assessment of Aboriginal parents for child welfare following the Truth and Reconciliation Commission. First Peoples Child and Family Review, 11(2), 45-59. Retrieved from http://journals.sfu.ca/fpcfr/ index.php/FPCFR/article/view/305

Lindstrom, G., Choate, P., Bastien, L., Weasel Traveller, A., Breaker, S., Breaker, C., ... Good Good Striker, E. (2016). Nistawatsimin: Exploring First Nations parenting: A literature review and expert consultation with Blackfoot Elders. Calgary, AB: Mount Royal University. Retrieved from https://www.researchgate.net/ publication/303544458_Nistawatsamin_EXPLORING_ FIRST NATIONS PARENTINGA LITERATURE REVIEW_AND_EXPERT_CONSULTATION

McCarthy, J. R., \& Gillies, V. (2018). Troubling children's families: Who is troubled and why? Approaches to intercultural dialogue. Sociological Research Online, 23(1), 219-244. https://doi.org/10.1177/13607804117746871

Mesman, J., van ljzendoorn, M., \& Sagi-Schwartz, A. (2016). Cross-cultural patterns of attachment: Universal and contextual dimensions. In J. Cassidy \& P. Shaver (Eds.). Handbook of attachment: Theory, research and clinical applications (3rd ed., pp. 852-877). New York, NY: Guilford

Miller, B. G. (2011). Oral history in trial: Recognizing Aboriginal narratives in court. Vancouver, BC: UBC Press.

Neckoway, R. (2011). The role of culture in parenting: Some Ojibway parents' perspectives. Memorial University of Newfoundland, St. John's Newfoundland and Labrador.

Neckoway, R., Brownlee, K., \& Castellan, B. (2007). Is attachment theory consistent with aboriginal parenting realities? First Peoples Child \& Family Review, 3(2), 65-74.

Ned, J. D., Frost, C. J. (Eds.). (2017). Contemporary issues in child welfare: American Indian and Canadian Aboriginal contexts. Vernon, BC: J. Charlton Publishing.

Racine v Woods. (1983). 2 SCR 173. Canada: Supreme Court. Retrieved from https://scc-csc.lexum.com/scc-csc/ scc-csc/en/item/2476/index.do

Simard, E. (2009). Culturally restorative child welfare practices: A special emphasis on cultural attachment theory. First Peoples Child \& Family Review, 4(2), 44-61.

Simard, E., \& Blight S. (2011). Developing a culturally restorative approach to Aboriginal child and youth development: Transitions to adulthood. First Peoples Child \& Family Review, 6(1), 28-55. 


\section{ORIGINAL ARTICLE}

\section{THEORETICAL RESEARCH}

Sinclair, R. (2007). Identity lost and found: Lessons from the sixties scoop. First Peoples Child and Family Review, 3(1), 65-82.

Stewart, J., \& Allan, J. (2013). Building relationships with Aboriginal people: A cultural mapping toolbox. Australian Social Work, 66(1), 118-129. http://dx.doi.org/10.1080/0 312407X.2012.708937

Truth and Reconciliation Commission of Canada. (2015). Honouring the truth, Reconciling for the future: Summary of the final report of the Truth and Reconciliation Commission of Canada. Retrieved from http://www. trc.ca/websites/trcinstitution/File/2015/Honouring_the Truth_Reconciling_for_the_Future_July_23_2015.pdf

van der Horst, F.C.P. (2011). John Bowlby - from psychoanalysis to ethology: Unraveling the roots of attachment theory. Sussex, UK: Wiley Blackwell.

van ljzendoorn, M. H., \& Sagi-Schwartz, A. (2008). Crosscultural patterns of attachment: Universal and contextual dimensions. In J. Cassidy \& P. R. Shaver (Eds.), Handbook of attachment: Theory, research, and clinical applications (pp. 880-905). New York, NY: The Guilford Press.

Vicedo, M. (2017). Putting attachment in its place: Disciplinary and cultural contexts. European Journal of Developmental Psychology, 14(6), 684-699. https://doi. org/10.1080/17405629.2017.1289838

Weisner, S. T. (2005). Attachment as a cultural and ecological problem with pluralistic solutions. Human Development, 48(1-2), 89-94. https://dx.doi.org/ doi:10.1159/000083219

White, S., Gibson, M., \& Wastell, D. (2019). Child protection and disorganized attachment: A critical commentary. Children and Youth Services Review, 105, October. https://doi.org/10.1016/j.childyouth.2019.104415

White, S., Gibson, M., Wastell, D., \& Walsh, P. (2020). Reassessing attachment theory in child welfare. Bristol, UK: Policy Press. 